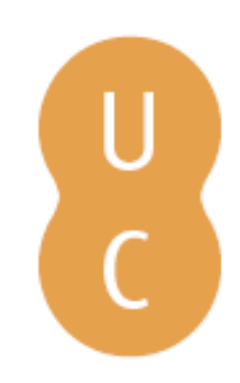

\title{
nommalina
}

\section{A transgressão da norma como forma de manter a ordem: uma nota sobre o sentido de $O$ político de Platão}

\author{
Autor(es): $\quad$ Monserrat Molas, Josep \\ Publicado por: Imprensa da Universidade de Coimbra \\ URL \\ persistente: URI:http://hdl.handle.net/10316.2/32803 \\ DOI: $\quad$ DOI:http://dx.doi.org/10.14195/978-989-26-0236-3_2 \\ Accessed : $\quad$ 26-Apr-2023 07:14:01
}

A navegação consulta e descarregamento dos títulos inseridos nas Bibliotecas Digitais UC Digitalis, UC Pombalina e UC Impactum, pressupõem a aceitação plena e sem reservas dos Termos e Condições de Uso destas Bibliotecas Digitais, disponíveis em https://digitalis.uc.pt/pt-pt/termos.

Conforme exposto nos referidos Termos e Condições de Uso, o descarregamento de títulos de acesso restrito requer uma licença válida de autorização devendo o utilizador aceder ao(s) documento(s) a partir de um endereço de IP da instituição detentora da supramencionada licença.

Ao utilizador é apenas permitido o descarregamento para uso pessoal, pelo que o emprego do(s) título(s) descarregado(s) para outro fim, designadamente comercial, carece de autorização do respetivo autor ou editor da obra.

Na medida em que todas as obras da UC Digitalis se encontram protegidas pelo Código do Direito de Autor e Direitos Conexos e demais legislação aplicável, toda a cópia, parcial ou total, deste documento, nos casos em que é legalmente admitida, deverá conter ou fazer-se acompanhar por este aviso.

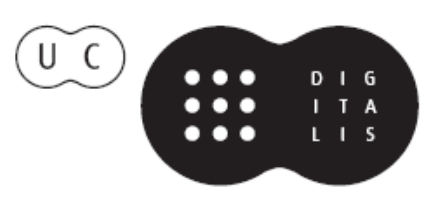


Carmen Soares

Maria do Céu Fialho

María Consuelo Alvarez Morán

Rosa María Iglesias Montiel

Coordenação

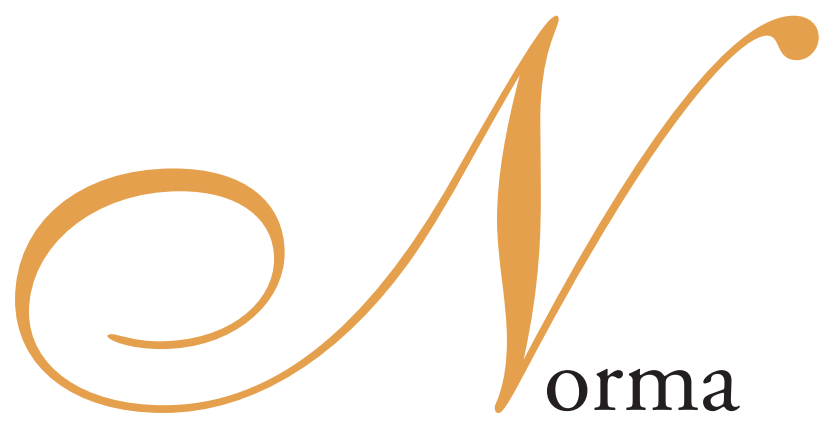

\& Transgressão

II

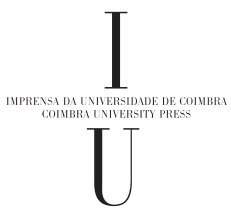


(Página deixada propositadamente em branco) 
Josep Monserrat Molas

Universidad de Barcelona ${ }^{1}$

\section{A TRANSGRESSÃO DA NORMA COMO FORMA DE MANTER A ORDEM:} uma nota sobre o SENTIDo de $O$ Político de Platão

Como tão oportunamente indicou M. Dixsaut (2007), as figuras femininas que pronunciam discursos nos diálogos platónicos mostram uma polaridade definida. Se, por um lado, Aspásia se destaca pela arte da sofística, e através dela Platão desmistifica todo um género caricaturando-o, por outro lado, Diotima realiza um elogio que só é válido se diz a verdade sobre a própria natureza do objecto de que se fala, no seu caso Eros, um mediador entre o humano e o divino. Deste modo, a relação de Platão com o feminino pode encontrar em O Político um novo motivo de reflexão, neste caso vinculado à arte de governo dos homens. No que diz respeito à questão acerca da norma e da transgressão, defendemos que a dinâmica sobre a qual é possível pensar a conservação e o progresso individuais e colectivos é também ela pensada em relação a uma figura feminina. A resolução de o político cumpre através de uma arte exclusivamente feminina (o tecer, neste caso de virtudes opostas) a demonstração do modelo e dos limites da verdadeira política possível. O sentido de O político reside na transmissão de uma responsabilidade partilhada de compreender o governo da cidade a partir da necessidade de defender a ordem precária com o contínuo fazer e desfazer que evita o caos e a tirania definitivos. Defendemos que a

\footnotetext{
1 Grup de Recerca 2009SGR447 «EIDOs: Hermenèutica, Platonisme i Modernitat», Universitat de Barcelona. Proyecto de Investigación financiado por la Dirección General de Investigación del Ministerio de Educación y Ciencia HUM2007-62763/FISO.
} 
complexidade dos referentes homéricos sobre que se situa o diálogo deve deslocar-se da referência a Ulisses como paradigma do senhor-rei-pastor divino para a figura de Penélope como aquela que mantém a ordem humana possível, através, precisamente, da transgressão da norma. Em primeiro lugar, expomos brevemente os princípios hermenêuticos a partir dos quais realizámos a presente exposição. Em seguida, trataremos, a partir de texto platónico, da própria questão da transgressão e da norma. Finalmente, mostraremos que aquela que se apresenta como uma verdadeira arte política é, concretamente, uma arte feminina, e o exemplo a partir do qual se constrói a definição da política e do diálogo o político é precisamente a história de uma transgressão que tem como objectivo salvar a ordem precária da cidade, ameaçada pela desordem e pela tirania.

\section{Leituras platónicas.}

O político de Platão apresenta-se-nos, com frequência, como um diálogo difícil e árido. Sustentamos que tal dificuldade e aridez não se traduzem, no entanto, num défice da sua qualidade artística ou da sua profundidade filosófica. Certamente, e talvez de um modo extremo, por comparação com o resto dos diálogos, a primeira impressão causada no leitor seja algo como uma ambiguidade ou uma indefinição inerente. É possível que a ambiguidade repouse na própria natureza dos diálogos platónicos: caso tenham sido escritos por um escritor em contínua evolução; caso sejam simplesmente amostras sem sentido para um público indiferenciado (enquanto que o ensino especializado ficava reservado ao interior da Academia); caso sejam o testemunho de um autor incapaz... Mas não temos razões suficientes para rectificar nenhuma das suposições anteriores. Antes pelo contrário, da análise detalhada dos diálogos platónicos, e de O político em particular, podemos inferir que são obras de arte extremamente elaboradas, que permitem, enquanto obras de arte que são, a realização de leituras de profundidade diversa e de ensaios sobre elas. Esse é o caso, como se defendeu recentemente, 
da indefinição que revelam os diálogos, e O político em particular, a qual resulta precisamente da dificuldade das próprias questões de que tratam: são questões que estão longe de estarem simplesmente resolvidas, e o mérito dos diálogos platónicos reside em colocá-las como fruto de uma compreensão profunda da totalidade da vida em que aparecem imersas (Monserrat 1999).

Este não é o momento de desenvolver detalhadamente os princípios hermenêuticos que nos levantam os diálogos platónicos e que nos permitiram encontrar neles um "conhecimento em situação" (Sales 1990). No entanto, é necessário pelo menos citá-los, para podermos apresentar o seguinte comentário, partilhado pelo nosso grupo de investigação.

"O sentido do projecto Hermenêutica e platonismo é apresentar a recepção da obra platónica como a captação de um ensinamento no exercício do nosso filosofar. Para isso, devemos tratar a forma dialógica como uma relação com um público e não como um simples invólucro de doutrinas ou como materiais para desenhar uma evolução ou uma trajectória, cuja recomposição fosse tarefa do filósofo platónico. No entanto, esta interpretação não implica optar por uma ou outra metodologia das actualmente vigentes no panorama dos estudos platónicos, mas antes atender à clarificação do texto através de recursos derivados de todas elas. Algo funciona mal num dilema entre uma leitura doutrinal e uma leitura dramática. [...] O que Platão constrói diante do leitor é o choque entre a interrogação socrática e a exibição de um saber que não é para si próprio um saber entre vários, mas sim um saber único e supremo. Na rivalidade entre saberes ou atitudes plurais, o exercício filosófico postula-se como tal [...] para encontrar a definição de uma estratégia de continuidade do socratismo frente a outras estratégias rivais" (Sales 2010).

As decisões metodológicas que impulsionaram os estudos platónicos e que inspiraram a trajectória da "Hermenêutica e platonismo" foram: a) as contribuições da escola de Tübingen, que revalorizam as fontes da tradição indirecta sobre as doutrinas não escritas e renovam o aspecto sistemático do platonismo, com as críticas pertinentes já realizadas; b) a forma de trabalhar própria de Leo Strauss, Jakob Klein, Seth Benardete, Stanley Rosen 
(Strauss 1964 [2000]; 1977; Klein 1965; Rosen 1987a; 1987b; 1995; 2007), etc., que atribui à significação da forma dialógica da escrita platónica uma importância decisiva. (O respeito pela forma do diálogo, por exemplo, proporciona-nos leituras a considerar atentamente, distantes de dogmáticos e cépticos, e extraordinariamente ricas, as quais mereceram o elogio de $\mathrm{H}$. G. Gadamer, apesar da sua divergência em relação aos seus princípios hermenêuticos fundamentais, Lastra 2000.) c) a continuação da filosofia husserliana da crise europeia nos escritos de Jan Patocka, sobretudo Platão e Europa, que modificou a concepção da tradição filosófica europeia (Patocka 1991, Fernández 1996).

Creio que podemos avançar com a seguinte conclusão: a actualidade na interpretação dos textos platónicos reside na convivência e na coincidência de diferentes modelos interpretativos ${ }^{2}$, na necessidade de manter uma distância crítica e no necessário respeito pela integridade do diálogo. Para interpretar um diálogo devemos afastar o mais que pudermos as nossas presunções sobre a natureza da filosofia: este é o requisito mais difícil de um intérprete alcançar e talvez não o atinja nunca ${ }^{3}$. Por isso iniciámos o nosso estudo com a questão da existência da filosofia, ligando-a à questão da sua natureza (Monserrat 2007).

Saber guardar as distâncias permite-nos aceder pouco a pouco à intimidade platónica sem sermos rejeitados. O diálogo platónico não é nem um tratado nem o texto de uma lição escolar. Os diálogos são, pela sua origem remota, uma variação das representações mímicas de Sofron e Xenarco. Nos diálogos

\footnotetext{
2 Gonzalez 1998: 21: "Furthermore, it is not the ambition of this collection finally to provide a definitive third interpretation to replace the traditional ones. It aims are more modest: to point out that there is a third way, to encourage its pursuit, and to provide some assistance in the form of preliminary and diverse maps of where it might be".

3 Gonzalez 1998: x: "Indeed, if there is one thing we must learn form Plato's dialogues, it is that we should always be willing to expose the questioning not simply some of our specific philosophical posititons, but even our most fundamental assumptions about the nature, point and value of philosophy. [...] the reason why none of the traditional paradigms have proven adequate is that they depend on one-sided and impoverished conception of philosophy that could never do justice to the much richer notion of philosophy in the dialogues. In this case we would indeed have much to gain from abandoning our preconceptions and actually learning from, wich for Plato means being transformed by, the dialogues".
} 
não conta apenas o que se diz, mas também o que se cala e o que se faz. Por outro lado, eles são variações em relação aos logoi sokratikoi, dos quais tomam as premissas, mas que superam no empenho pela preservação da memória de Sócrates (Kahn 1996). Os diálogos estão impregnados de seriedade e jocosidade, de comédia e de tragédia, e ambos os aspectos são igualmente importantes. Especialmente esclarecedora é a leitura final do Banquete, onde nos é narrado como Sócrates parte acordado, depois de o actor da tragédia e o da comédia terem adormecido (Sales 1996). O leitor assiste como actor mudo à conversa que tem lugar diante dele: corresponde ao leitor-ouvinte silencioso aceitar ou rejeitar aquilo que se lhe apresenta. Deve respeitar-se a distância entre a cena e o leitor para poder situar o olhar e ver ouvindo. O diálogo responde a uma estratégia comunicativa que deve ser valorizada. Os diálogos não são a expressão aproblemática da doutrina ou do sistema platónico. Para não cairmos no que Charles Kahn (1996: 42) chamou "a falácia da transparência" ${ }^{4}$, devemos prestar atenção a um facto evidente: em vez de aparecer nos diálogos, Platão apresenta-nos diferentes personagens numa conversa que pretende representar a vida da filosofia na cidade. Não é evidente a existência de um porta-voz platónico5 De pouco servem as remissões para outros diálogos, se não se toma em consideração que o corpus platonicum não conforma aproblematicamente uma unidade orgânica: o contexto dialógico particular de cada texto é indispensável para entender toda e qualquer afirmação.

Pelo contrário, cada diálogo é uma unidade indissociável de forma e de conteúdo: de nada serve recorrer a um fragmento, se não se considera

\footnotetext{
${ }^{4}$ Cf. Lamb 1811 (in Bate, 1997: 112): "But such is the instantaneous nature of the impressions which we take in at the eye and ear at a playhouse, compared with the slow apprehension oftentimes of the understanding in reading, that we are apt not only to sink the play-writer in the consideration which we pay to the actor, but even to identity in or minds in a perverse manner, the actor with the character which he represents."

5 Para uma discussão sobre o anonimato platónico, veja-se L. Edelstein (1962: 16), que insiste com razão que Platão não pode ser identificado com nenhuma das suas personagens e que Platão "always preserves his anonymity, but conceals himself in various ways, just as he retains the dialogue form in all his works, although he gives in many variations [...] This use of many marks constitutes a unique feature of Platonic anonymity".
} 
suficientemente o contexto dialógico do qual foi extraído e que o sustentava. Deve atentar-se com cuidado em tudo o que se diz e se faz num diálogo, de acordo com o chamado princípio da necessidade logográfica: os detalhes podem esclarecer mais do que os longos discursos. Constitui um princípio hermenêutico considerar a possibilidade de que Platão não tenha dito nada em vão ${ }^{6}$. Deve distinguir-se a ironia intradialógica, entre as personagens, da ironia platónica, aquela que Platão busca através da disposição da cena, das personagens, dos argumentos, etc. (Griswold 1988).

Estes princípios de leitura devem combinar-se necessariamente com uma tarefa de depuração de tudo aquilo que a crítica juntou aos diálogos na discussão de problemas que não pertencem aos diálogos, processo que se realizou naturalmente, através da técnica de retirar os textos do seu contexto, recolocando-os num leito de Procusto de problemas anacrónicos. Deve realizar-se um esforço de catarsis e discutir as interpretações mais sólidas, colocando-as entre parêntesis. Deve tomar-se em consideração a estratégia comunicativa platónica: enquanto uns testemunhos falam de uma função protréptica do diálogo, outros falam de prolepsis. Finalmente, não se pode descartar a presença, quer seja simplesmente assinalada quer seja como estrutura compositora, de uma doutrina dos princípios, da qual nos falam os testemunhos.

Depois de estabelecer de forma sumária estas notas prévias, acrescento, para terminar este primeiro ponto da minha intervenção, uma reflexão final sobre o conteúdo e a forma. Porque é que a interpretação do platonismo é um dos problemas fundamentais da presente actualidade filosófica? Pelo menos pela seguinte razão: o modelo do filósofo ou do intelectual herdado do Iluminismo, herdou também o problema das relações com o despotismo e com as suas recentes variações totalitárias ou, ainda, com as variações mais recentes, oligárquicas. Em muitas ocasiões, a cena dramática platónica que envolve a o diálogo coloca-nos perto de futuros filósofos e de futuros tiranos de uma forma muito mais avisada do que a inocência ilustrada (Sales 1999: xxii).

\footnotetext{
6 J.-F. Mattéi 1996: 112: "Platon et la nature ne font jamais rien en vain".
} 
O hermetismo do texto platónico reside no facto de, no diálogo, a questão aparecer a par dos aspectos que obstam à sua clareza. A situação do platonismo é a de não continuidade da tradição: continua a falar porque está à procura da questão que seja capaz ou não de o abrir. E para acabar este primeiro ponto, em forma de síntese, podemos afirmar o seguinte: um diálogo platónico é uma fenomenologia dramática, que, através da descrição feita pelas personagens, do argumento discursivo e dos factos retratados na cena, desenha uma ficção que nos situa como espectadores-ouvintesleitores e que espera de nós uma resposta, para que o acto comunicativo que o diálogo busca fique completo (Klein 1977, Brague 1978, Sales 1992, 1996). Para estes fins trabalha a arte de escrever de Platão.

Uma arte em relação à qual dispomos de testemunhos da sua meticulosidade: por exemplo, dando conta que o filósofo trabalhou incessantemente na correcção dos seus escritos; ou, e para as minhas investigações este feito resultou especialmente significativo, o facto de o prefácio do Teeteto que, segundo consta, redigiu de novo, ocupar exactamente o mesmo número de linhas que o anterior. Platão emprega uma arte de escrever de que ainda não conhecemos todas as chaves, mas que continua a convidar-nos para o exercício atento da inteligência que é a leitura. Realmente Platão consegue, com a sua escrita, a construção de um texto que reclama incessantemente que se medite sobre ele (Monserrat 2003).

\section{A "segunda navegação»: dos legisladores à dupla fundamentação da lei ( $O$ político 300a-302a).}

Numa importante passagem de O político de Platão, o Estrangeiro defende que pior do que uma situação de leis más seria a situação em que o governante actuasse à margem da lei escrita por benefício próprio ou por capricho. A passagem está marcada de forma estilística através da repetição das palavras iniciais do diálogo: os agradecimentos. O jovem interlocutor do Estrangeiro de Eleia, um jovem discípulo de Teodoro, chamado Sócrates, 
reconhece que esta afirmação do Estrangeiro é uma grande verdade. Neste momento do diálogo procede-se a uma revalorização das leis, depois de submetidas a uma crítica explícita pela sua inadequação aos problemas da realidade. De forma evidente, é estabelecido que a primeira imitação da constituição perfeita seria o regime sustentado por leis baseadas na experiência através do conselho de peritos, que ensinam o povo a promulgálas e a defendê-las. Neste momento ficam estabelecidos de forma clara todos os elementos que entram em jogo na dimensão política. No entanto, é necessário um expediente acessório, a segunda navegação.

A segunda navegação de O Político de Platão consiste na proibição de desobedecer às leis (segunda navegação: Phaed. 99c, Phileb. 19c, Leg. $875 d$ y Epist. VII 337c). No entanto, esta restrição aplica-se aos indivíduos particulares e à multidão (méte héna méte plêthos). Não ficará sem considerar, entre estes dois extremos, a possibilidade de uma intervenção política transgressora em relação à norma, no momento oportuno, por parte daqueles que dedicaram o seu tempo livre com os amigos à análise da cidade e à procura da verdade (Epist. VII)?

O jovem Sócrates julga adequada tal proibição. Pois bem, o Estrangeiro, que nesta última resposta pode ter sido ambíguo, na tentativa de promover leis excessivamente referenciáveis, procurará agora arrancar o jovem Sócrates da sua submissão à legalidade excessiva. O problema fundamental é garantir, ao mesmo tempo, o vigor e a perfeição da "constituição».

As leis e os costumes desenhados pelos entendidos (ou peritos) são imitações da verdade. O verdadeiro político, insiste-se, tomava muitas decisões, de acordo com a sua arte, sem estar preocupado com as normas escritas, sempre que aqueles fossem melhores do que as que ele próprio redigira e enviara a pessoas distantes ou ausentes (Rowe 1995: 231).

Ao invés, muitos dos que, perante as leis vigentes, as transgridem para procurar uma alternativa pensando que esta é preferível, e actuam, dentro das suas possibilidades, como o legislador autêntico, caso não possuam a ciência, esses obtêm uma imitação que será péssima; mas, se forem técnicos especializados, então não obterão uma imitação, mas sim a verdade. 
A possibilidade legislativa que nos apresenta dificilmente se encontrará no meio-termo possível entre a multidão informe e o uno divino, enquanto acção política oportuna e prudente.

Como ainda permanece o acordo segundo o qual a multidão é incapaz de adquirir uma técnica ou arte (293a2-4 e 297b7-c2.), o diálogo determina que, se existir uma arte real, nem a multidão de ricos nem o conjunto do povo a possuirá, uma vez que são incapazes de possuir o saber político. Perante esta dificuldade, as cidades, para imitar a constituição autêntica, devem abster-se de fazer o que quer que seja contra as leis escritas ou as normas pátrias, se estas estiverem em vigor. Para um regime com uma existência histórica, imitar a única constituição verdadeira significa respeitar as leis criadas, um caso claro de conservadorismo. O jovem Sócrates expressa neste caso o seu consentimento de forma entusiasta (o texto permite pensar numa conversão do jovem ao "constitucionalismo": Gill 1995: 292-305).

O argumento só seria válido se a acção política estivesse dominada exclusivamente pela unidade e pela multiplicidade. Em vez de mencionar outra possibilidade, o texto limita-se a considerar o nome a atribuir aos regimes consoante os seus governos respeitem ou não as leis. Se governam os ricos (boy ploúsioi -o texto não diz os poucos-) ${ }^{7}$, e se cumpre a condição que acabámos de explicitar, ou seja, se fazem a imitação através da observação das leis, chamamos-lhe aristocracia, caso contrário oligarquia. Um homem que governe segundo as leis é denominado rei. Com o nome de rei (basileus) não se distingue quem governa segundo as leis por saber ou quem o faz com base na opinião (cf. a oposição dóxa-epistéme em Resp. 476d ss). É tanto rei o verdadeiro político como o monarca que governa segundo as leis. Como tinha dito o Estrangeiro, embora agora não se faça uso de distinções ao nível da linguagem, é evidente que a identificação é errónea. O primeiro tem saber e o segundo é apenas detentor de opinião ${ }^{8}$.

\footnotetext{
7 Cf. em 298e "escolher entre ricos e o povo", e em 292d: "o governo de uns poucos" (oligón).

8 Cf. Theaet. 201a-c, a opinião correcta obtém-se a partir do que dizem aqueles que possuem ciência. Vd. Cambiano 1971: 133-136, Ibáñez 2007. Em Conv. $202 a$ la opinião correcta
} 
Embora o texto grego dos códices não apresente variações, a frase seguinte foi alterada por Diès e alguns outros editores que o seguem?. O texto grego, sem modificar a tradução, seria: "Por isso", diz o Estrangeiro, «Os cinco nomes das constituições agora mencionadas convertem-se num só»(301b).

O sentido é o seguinte: o Estrangeiro extrai uma conclusão brusca da afirmação feita anteriormente em 293c5-7, segundo a qual a constituição correcta é a única constituição. Se a única constituição é a realeza, então dos cinco nomes habituais apenas seria necessário um. O resultado é uma lista de cinco nomes: tirano, rei, oligarquia, aristocracia e democracia. Os dois primeiros, que são as duas possibilidades de governo de um só, correspondem aos governantes, os três últimos a formas de governo. Contudo, o Estrangeiro reserva, nesta intervenção, o nome monarquia àquela forma anterior que deixámos de lado porque os homens desconfiam que ninguém pode merecer o governo que o saber proporciona e que permitiria a distribuição correcta do que é justo e piedoso.

Pensa-se, antes, que quem possuísse esse poder, sem submeter-se às leis, assassinaria, maltrataria e prejudicaria; seria um tirano. Mas também acontece que, se é só um a governar à margem das leis e dos costumes, e finge ${ }^{10}$ fazer o melhor, como se fosse o esperado perito, à margem das leis escritas, neste caso os verdadeiros guias da sua acção serão a paixão e o desconhecimento daquilo que deve imitar-se, e, por isso, recebe o nome de tirano (Resp.572e ss.). Por outro lado, aquele que parece ser um político acima da lei e da norma acaba por, baseado na ignorância e no erro, constituir a distorção extrema da boa política. No entanto, o caso descrito anteriormente seria antes o daquele que pilotara (diakubernônta) de forma feliz a nave do único regime correcto, que está para além das normas escritas.

\footnotetext{
é o meio termo entre a ciência e a ignorância e, ao contrário da ciência, não sabe dar sinal de si. Em Menon 97 a ss a opinião certa pode assegurar a correcção da actuação.

9 Rowe 1995, Accatino 1997, Balasch 1997, Soares: 2008. A correcção proposta por Diès 1935: 75n1 discute-a Skemp 1952/1987: 211.

10 Homenagem da tirania ao bom governo.
} 
O jovem Sócrates está de acordo com tal argumentação. No entanto, o Estrangeiro acrescenta que nas cidades não existe nenhum rei desse tipo, como o que cresce nos enxames de abelhas, nos quais a rainha se distingue das outras abelhas no corpo e na alma ${ }^{11}$. Prestemos agora atenção ao facto de se estar repetindo o esquema que o mito anteriormente enunciado pretendia corrigir: parece que regressamos à figura do pastor de povos, semelhante a um deus, mas diferente por natureza dos animais do rebanho. Visto que essa situação (que possa existir tal ser excepcional) não pode ser real, então, prossegue o Estrangeiro, é necessário «as pessoas reunirem-se para redigir as leis seguindo a orientação da mais verdadeira das constituições» (301e).

O jovem não parece estar tão seguro como antes, pois responde "provavelmente". Talvez por se ter dado nitidamente conta da impossibilidade de concretização do primeiro modelo.

O Estrangeiro volta a dirigir-se ao seu interlocutor pelo nome na conclusão deste passo, e então acrescenta que não são de estranhar as desgraças que sucedem aos regimes políticos que seguem as normas escritas e os costumes, mas apenas que não actuam (práxeis) seguindo um saber (episteme). Deste modo repete-se a necessidade de um fundamento constitucional para além da letra de texto, a necessidade de uma arte de ajustes, sobre a qual a arte política deve fundamentar-se para que o resultado não seja destrutivo.

O que surpreende é a resistência que, naturalmente (phýsei), a cidade oferece, pois actualmente as cidades encontram-se nessa circunstância e resistem durante bastante tempo, sem se afundarem ou arruinarem, apesar dos governantes e das normas que têm. Contudo, tal facto não representa uma objecção à desgraça de um mau fundamento político porque, como continua o Estrangeiro, muitas cidades "indo ao fundo como navios, destroem-se, destruíram-se e ainda hão-de continuar a destruir-se" devido à perversidade dos seus pilotos e tripulantes,

\footnotetext{
${ }^{11}$ O enxame foi o exemplo utilizado em 293d, precisamente a propósito das constituições das cidades. Cf. Arist. Pol.VII 14, 1332b. Sobre as abelhas como exemplo da educação dos filósofos: Resp. 489e ss. Cf. 492a. Xenofonte diz de Ciro que é um rei por natureza, como a rainha das abelhas (Cirop. 5. 1. 24). Em Leg. 694c Ciro não seria rei porque não era educado. Sales \& Monserrat 2009.
} 
que revelam a maior ignorância em relação às coisas de máxima importância: não sabem nada de política e crêem que é precisamente este saber aquele que dominam melhor entre todos os saberes» (302ab).

O jovem concorda com o Estrangeiro, dizendo que essa é uma grande verdade (alethéstata). Com este acordo termina esta parte, pois logo a seguir o diálogo termina (302c5), terminando também a reiterada imagem da nave, metáfora tanto do governo da cidade como da própria cidade, mas com uns ténues acrescentos que não deixam de ser relevantes. Se de início a responsabilidade do navio cabia ao seu piloto, agora fala-se «da perversidade dos pilotos e tripulantes» (kybernetôn kaì nautôn mokhtherian) como sendo o factor responsável pelo seu afundamento e desaparecimento.

A razão desta argumentação é muito clara: este não é o piloto originário (nem é o deus que abandona o universo ao mar infinito da indiferença), que conhece o que é necessário; trata-se, antes, de pilotos completamente ignorantes das matérias de primeira importância, as quais são objecto de estudo da filosofia. Não sabem nada de política e pensam que sabem aquilo que não sabem. Repare-se que se chama a atenção para o facto de a responsabilidade ser partilhada. Em toda esta parte do texto cabe à cidade aceitar o governante. A cidadania, no seu todo, desempenha um papel que deve ser ponderado.

A nave da cidade está nas mãos de quem está. Perante «esta evidência»o Estrangeiro passará a tratar do mal menor: qual das constituições incorrecta é a melhor para se viver. Entramos no meio de uma cheia que transbordará as margens da argumentação, tal como um rio que tudo inunda quando sai do seu leito. Se a transgressão é necessária e benéfica para corrigir a norma caduca, é, no entanto, destruidora quando salta as margens que protegem a vida.

\section{O político de Platão como um tecido. A política como um tecido. O tecido de Penélope.}

Cornélius Castoriadis considera que a eleição da arte de tecer como paradigma da política é um dos episódios mais arbitrários da literatura 
universal (Castoriadis 1999). Apesar de o texto indicar que tal eleição se faz porque não há nada melhor à mão, uma análise correcta desta passagem permite observar que a eleição, contra aquilo que pensa Castoriadis, não é um acto arbitrário.

Muito conhecida é a comparação que em O político de Platão se estabelece entre "a arte da política" e "a arte de tecer". Iremos procurar agora demonstrar que o paradigma ou modelo da arte de tecer é precisamente o modelo de construção do diálogo e das suas partes. Além disso, teremos também em conta a natureza feminina de tal arte e, de forma explícita, a imagem concreta sobre a qual o diálogo, aos olhos do leitor contemporâneo, se constrói: o relato que Homero nos oferece na Odisseia da confecção de uma teia por parte de Penélope, com a qual evita durante algum tempo o seu matrimónio com um dos pretendentes ao trono de Ítaca. ${ }^{12}$

Quem conhece o diálogo platónico, e incentivo à leitura da sua recente tradução para português da autoria de Carmen Soares, recordará que a política é por fim definida como a arte de entrelaçar os diferentes caracteres presentes na cidade, por forma a obter um tecido que a proteja. Os caracteres que se mencionam são os dotados de coragem e os dotados de moderação. O labor do verdadeiro político consiste em tecê-los como se tece a urdidura (fio forte) e a trama (fio flexível) para conseguir uma teia apropriada. Assim, para além do detalhado método de diérese, através do qual o Estrangeiro de Eleia alcança uma definição da política similar à da arte de tecer, é extraordinariamente surpreendente como o próprio diálogo, e refiro-me aqui ao próprio texto do diálogo, se nos apresenta, numa perspectiva material e simbólica, como o resultado da acção de tecer, e mais concretamente, como a própria acção de tecer de Penélope. Falo numa perspectiva material, porque o diálogo se faz ou tece, quando entrelaça a urdidura (o Estrangeiro de Eleia) com a trama (o jovem Sócrates); também material,

\footnotetext{
12 Seguimos com atencão os trabalhos de Z. Planninc, que apresentam várias novidades no que se refere à presença de imagens homéricas equivalentes em muitos outros diálogos platónicos. Cf. Planninc "Equivalències d'experiència i simbolització en Plató i Homer", in Anuari de la Societat Catalana de Filosofia, XIX, 2008.
} 
quando o diálogo se desfaz nas repetidas diéreses (como por exemplo aquela que se faz para conseguir separar o verdadeiro político de todos os pretendentes e de todos os potenciais candidatos), processo que consiste no método de separação em dois, tal como acontece quando se separam os fios. Falo numa perspectiva simbólica, porque, se a finalidade do tecido de Penélope é salvar a cidade do caos, a finalidade do tecido das virtudes, obra a que se dedica o verdadeiro político, é a de salvar a cidade.

Mais ainda, nem um tecido (o de Penélope) nem o outro (o do político) alcança ou tem a pretensão de impor um regime político de salvação; apenas servem para ganhar tempo contra a decadência que aguarda nas esquinas da mansão de Ulisses ou junto aos muros da cidade. Mas não é simplesmente esta luta contra o inevitável o papel que aguarda a filosofia na antiguidade? E não é precisamente outra grande figura feminina de Platão, Diotima, a sacerdotisa de Mantineia que descobre a Sócrates os segredos de eros e portanto da filosofia, aquela que tem o mérito de retardar durante dez anos a peste que aguarda Atenas (Conv. 201d)?

Além disso, demonstrámos já noutro lugar como a estrutura de composição do diálogo se constrói simetricamente a partir do enlace das diferentes partes do texto sobre um eixo central, coincidente com a reflexão sobre a justa medida (Monserrat 2003). De facto, a redacção do diálogo não foi mais do que entrelaçar essa estrutura simétrica rígida com o desenvolvimento elástico de um diálogo entre interlocutores. E inclusive a estrutura mecânica do cosmos explicitado no famoso mito que aparece no diálogo, o mito das idades de Cronos e Zeus, responde seguramente a um modelo construído seguindo a mecânica da técnica de fiar (Schuhl 1947: 71-78, 79-89).

Por isso é evidente que, quando o Estrangeiro propõe a arte de tecer como exemplo, não se trata de uma arbitrariedade, e tê-lo "meramente à mão" é mais um exemplo da ironia platónica, ironia essa que não se deve confundir com a ironia socrática. Fica então enriquecida e apresenta-se-nos merecedora de uma reflexão, a tese segundo a qual aquela que se propõe como arte da política é um labor feminino. 
Nos versos 567-587 da Lisístrata de Aristófanes, a arte de tecer, uma actividade feminina, como também Platão deixa claro em Leis 805e-806a, é proposta ao magistrado da cidade como modelo corrector. Se este magistrado possuísse algum senso comum, diz-lhe Lisístrata, seguiria na política o exemplo que as mulheres proporcionam com as suas lãs. Em Aristófanes vemos que o aspecto cómico se acentua quando se apresenta, como exemplo e modelo de uma actividade "masculina", uma mulher e uma tarefa própria das mulheres.

Noutros testemunhos, Sócrates aparece por vezes a referir-se a esta arte feminina, especialmente em Xenofonte: "[Sócrates] dava a entender que na arte de fiar, as mulheres superam os homens, porque sabem, e eles não entendem nada”, Mem. 10). Em A república de Platão, Sócrates pergunta a si mesmo "Ou vamos perder tempo a falar da tecelagem ou da arte da doçaria e da culinária, nas quais parece que o sexo feminino deve marcar, e, quando é derrotado, não há nada de mais risível?" ( $455 \mathrm{~cd}$. trad. de M. H. Rocha Pereira). Cf. uma contrapartida mordaz em Juvenal, Sat. I (FBM II 54-57).) Em Teeteto, a tarefa socrática relaciona-se com a das parteiras, como era o caso da sua mãe (cf. Ibáñez, 2007). A passagem de O político não é, portanto, excepcionalmente singular. Assim, podemos interrogar-nos se também esta remissão para uma arte "feminina", a arte de tecer, exerce no diálogo platónico a função de denegrir a figura tradicional do político-soberano-divino, "masculino", como poderia ser apresentá-lo a correr ao lado do porqueiro $(266 c d)$.

Apesar de o diálogo de que tratamos avançar de forma significativa acumulando erros, pensamos que, no seu conjunto, as correcções e as divagações contribuem para um aumento dos dados que devem tomar-se em consideração numa possível elucidação do problema. Se por um lado constatámos que, na correcção parcial da diérese, nos escapava a possibilidade de um benefício que resultaria de considerar como a política poderia ser algo situado entre o uno e o múltiplo (entre o automatismo despótico do saber e a indolência paradisíaca do rebanho), por outro, pudemos corrigir a figura do pastor com a incorporação da aceitação voluntária por parte do rebanho. Se por um lado constatámos que os modelos ou paradigmas que 
exemplificam as coisas de um nível superior dificilmente cumprem com a sua tarefa de exemplo, por outro, estabelecemos um paradigma ou modelo da política através da utilização da arte de tecer (algo que se reconhece como claramente inferior).

Em suma, o paradigma e a coisa a ser explicada, a arte de tecer e a politica, foram estudados de forma equívoca e confusa. A aplicação do método diurético próprio da reflexão científico-matemática provocou erros, devido à abstracção de valores como a beleza ou a honra. O Estrangeiro cometeu erros para provar ao jovem Sócrates determinados pontos. O jovem cometeu erros devido à sua inexperiência e à sua idade quase infantil. Apesar de tudo, essa acumulação platónica de erros mostrou-nos em que medida estes são pouco evitáveis, ou então que evitá-los, numa correcção pouco cuidadosa, leva inclusive a mais e maiores erros. A conclusão intra-dialógica, no entanto, não é o desfalecimento perante o repetido fracasso, mas antes a coragem da procura, que se sabe errada, mas que ainda serve para alimentar alguma esperança, num saber próprio do erro e da admissão da necessidade de correcção.

Os diálogos platónicos são um tecido formado de seriedade e chacota. Vimos como pode ser "cómico" o recurso à arte de tecer. Agora perguntamos: Não será esta chacota o sinal de uma correcção que reclama algo de feminino como uma constante dos diálogos platónicos? Deve deixar-se em aberto a possibilidade de que a arte de tecer, uma arte feminina, possa actuar em relação à política tal como Diotima com o jovem Sócrates de O Banquete, transformando o seu egoísmo narcisista em amor à Beleza em si, ou como Aspásia no Menexeno sobre a retórica do patriotismo, transformada num interesse comum.

Perante a esterilidade do uno homogéneo (Amón), também em O Político "o elemento feminino é necessário para produzir a paz e a justiça na cidade e para entrelaçar o homem com os deuses" (Sales 1996: 66). Não esqueçamos que tudo no seu conjunto, e explicitamente O Político, se entrega à boa vontade das Graças que presidem ao diálogo. A transgressão da norma que implica a presença do feminino na dimensão culturalmente masculina do poder é um caminho platónico proposto para pensar e conseguir uma cidade que evite a destruição pela mentira, pela fealdade e pela perversidade. 


\section{Bibliografia}

Accatino, P. (1997) Platone. Politico. Bari: Laterza.

Balasch, M. (1997) Plató. Diàlegs. vol. XVI. El polític. Barcelona: Fundació Bernat Metge

Brague R. (1978) Le restant. Supplément aux commentaires du Ménon de Platon, Paris: Les Belles Lettres.

Cambiano, G. (1971) Platone e le techniche. Roma: Bari.

Castoriadis, C. (1999) Sur "Le Politique» de Platon, Paris: Éditions du Seuil.

Diès, A. (1935) PLATON. Oeuvres Complètes, IX/1, Le politique, Paris: Les Belles Lettres.

Dixsaut, M. (2007) "Les philosophes et les femmes», Le Nouvel Observateur, Dossier, 16-22. VII.2007.

Edelstein, L. (1962) "Platonic Anonymity", American Journal of Philosophy 83: 1-22.

Fernández, F. (1996) Jan Patocka. La filosofia en temps de lluita, Barcelona: Barcelonesa d'Edicions.

Gill, C. (1995) "Rethinking constitutionalism in Statesman 291-303", in C. J. Rowe (ed.), Reading the Statesman. Proceedings of the Symposium Platonicum III, Sankt Agustin: Akademia Verlag, 1995: 292-305.

Gonzalez, F.J. (1998) Dialectic and Dialogue. Plato's Practice of Philosophical Inquiry, Evanston: Northwestern UP.

Griswold, C. L. (1988) Platonic Writings, Platonic Readings, New York: Routledge.

Ibáñez Puig, X. (2007). Lectura del Teetet de Plató. Saviesa i prudència en el Tribunal del Saber, Barcelona: Barcelonesa d'Edicions.

Kahn, Ch. (1996) Plato and the Socratic Dialogue. The Philosophical Use of a Literary Form, Cambidge: Cambridge UP.

Klein, J. (1965) A Commentary on Plato's Meno, The University of North Carolina Press.

Klein, J. (1977) Plato's Trilogy, Chicago \& London: University of Chicago Press.

Lamb, Ch. (1811) «On the Tragedies of Shakespeare, considered with reference to their fitness for stage representation" en J. Bate (ed.), The Romantics on Shakespeare, London: Penguin Books, 1997.

Lastra, A. (2000) La naturaleza de la filosofía politica. Un ensayo sobre Leo Strauss, Murcia: Res Publica.

Mattéi, J.F. (1996) Pythagore et les pythagoriciens, Paris: PUF.

Monserrat Molas, J. (1999) El polític de Plató. La gràcia de la mesura, Barcelona: Barcelonesa d'Edicions.

Monserrat Molas, J. (2003) "La mesure comme principe constitutif du Politique de Platon", Revue de Philosophie Ancienne, 2003/1: 3-22.

Monserrat Molas, J. (2007) Estranys, setciènies o pentatletes, cap. IV: "Rivals o amants: Rivals d'amor. Comentari al platònic Anterastai, Barcelona: Barcelonesa d'Edicions.

Patocka, J. (1991) Platón y Europa. Barcelona: Península 1991.

Planning, Z. (2008) "Equivalències d'experiència i simbolització en Plató i Homer», Anuari de la Societat Catalana de Filosofia, XIX: 133-139.

Rosen, S. (1987) Plato's Sophist, New Haven \& London: Yale University Press.

Rosen, S. (1987, 2a ed.) Plato's Symposium, New Haven \& London: Yale UP.

Rosen, S. (1995) Plato's Statesman. The Web of Politics, New Haven \& London: Yale UP. 
Rosen, S. (2007) Filosofia fundadora. Estudis per a una metafísica del present, edició de X. Ibáñez-Puig i J. Monserrat Molas, Barcelona: Barcelonesa d'Edicions.

Rowe, C. (1995) Plato. Statesman, Warminster: Aris \& Philips.

Sales, J. (1990) Coneixement i situació. Barcelona: PPU [2 ${ }^{\mathrm{a}}$ ed. Barcelona: Barcelonesa d'Edicions, 2010].

Sales, J. (1992) Estudis sobre l'ensenyament platònic, I : Figures $i$ desplaçaments, Barcelona : Anthropos.

Sales, J. (1996) A la flama del vi. El Convit platònic, filosofia de la transmissió, Barcelona: Barcelonesa d'Edicions.

Sales, J. (1999) "Assistir al diàleg, assistir el diàleg», in Monserrat 1999: xv-xxiv.

Sales, J. \& Monserrat, J. 2009. "A more political animal than bees: Polity as an intermediate state, as the highest state, or as an agent of stability", Studia Neoaristotelica 6/1: 3-14.

Sales, J. (2010). “¿Diálogos 'socràticos? ¿Con y sin areté?» Texto inédito: pro manuscripto.

Schuhl , P.M (1947) Études sur la fabulation platonicienne, Paris: Vrin.

Soares, C. (2008) Platâo. O Político, Círculo de Lectores e Temas e Debates.

Skemp, J.B. (1957) Plato. Statesman. New Haven \& Bristol: Bristol Classical Press [2002

Strauss, L. (1964) The City and Man, Chicago \& London: University of Chicago Press [La ciutat i l’home, traducción de J. Galí y J. Monserrat, Barcelona: Barcelonesa d'Edicions, 2000]

Strauss, L. (1977) The Argument and the Action of Plato's Laws, Chicago \& London: University of Chicago Press. 


\section{Série}

\section{Documentos}

Imprensa da Universidade de Coimbra

Coimbra University Press

2011

- $\mathrm{U}$

C • 